\title{
Estimated Emission Reductions from California's Enhanced Smog Check Program
}

Brett C. Singer and Thomas P. Wenzel*

E.O. Lawrence Berkeley National Laboratory, Berkeley, CA 94720

\begin{abstract}
EPA requires that states evaluate the effectiveness of their vehicle emissions inspection and maintenance $(\mathrm{I} / \mathrm{M})$ programs. This study demonstrates an evaluation approach that estimates mass emission reductions over time and includes the effect of $\mathrm{I} / \mathrm{M}$ on vehicle deterioration. It includes a quantitative assessment of benefits from pre-inspection maintenance and repairs and accounts for the selection bias effect that occurs when intermittent high emitters are tested. We report estimates of one-cycle emission benefits of California's Enhanced Smog Check program, circa 1999. Program benefits equivalent to tons per day of prevented emissions were calculated with a "bottom-up" approach that combined average per-vehicle reductions in mass emission rates (g/gal) with average per-vehicle activity, resolved by model year. Accelerated simulation mode test data from the statewide vehicle information database (VID) and from roadside Smog Check testing were used to determine two-year emission profiles of vehicles passing through Smog Check and infer emission profiles that would occur without Smog Check. The number of vehicles participating in Smog Check was also determined from the VID. We estimate that in 1999 Smog Check reduced tailpipe emissions of $\mathrm{HC}, \mathrm{CO}$, and $\mathrm{NO}_{\mathrm{X}}$ by 97, 1690 and 81 tons per day, respectively. These estimates are highly sensitive to assumptions about vehicle deterioration in the absence of Smog Check. Considering the estimated uncertainty in these assumptions yields a range for calculated benefits: 46 to 128 tons per day of $\mathrm{HC}, 860$ to 2200 tons per day of CO, and 60 to 91 tons per day of $\mathrm{NO}_{\mathrm{X}}$. Repair of vehicles that failed an initial, official Smog Check appears to be the most important mechanism of emission reductions, but pre-inspection maintenance and repair also contributed substantially. Benefits from removal of non-passing vehicles accounted for a small portion of total benefits. In 1999, more than $90 \%$ of all HC and $\mathrm{CO}$ benefits, and over $80 \%$ of all $\mathrm{NO}_{\mathrm{X}}$ benefits, were attributed to vehicles more than 10 years old, even though such vehicles represented only half of those tested in the program.
\end{abstract}

Key words: Motor vehicle emissions; Inspection and maintenance; Air pollution reduction. * Phone: 510-486-5753; Fax: 510-486-6996; TPWenzel@lbl.gov 


\section{Introduction}

The "Smog Check" vehicle inspection and maintenance (I/M) program has been a fixture of air pollution control efforts in California since the mid 1980s. Smog Check and other state I/M programs require that vehicles be tested to ensure that their pollutant emissions are below allowable levels and/or that their emission control systems are functioning properly. Highemitting or malfunctioning vehicles are required to be repaired. Vehicles that cannot be repaired adequately are barred from registration in the polluted area and theoretically must be retired or migrate to an area with less stringent I/M requirements. Emission reductions are thus achieved through both repair and accelerated retirement of vehicles. Emission reductions that result from vehicle maintenance and repairs performed in preparation for an I/M test also may be credited as pre-inspection benefits of an I/M program.

Until recently Smog Check consisted primarily of a biennial "two speed idle" test in which tailpipe emissions were measured with the transmission in neutral and the engine running at 1000 then 2500 revolutions per minute. In response to U.S. Environmental Protection Agency (EPA) requirements, California instituted the Enhanced Smog Check program in June 1998. The Enhanced program applies to areas of the state with particularly bad air quality, i.e., the Los Angeles, San Diego, Sacramento, and Central Valley air basins. One key feature of the Enhanced program is the Acceleration Simulation Mode (ASM) test, which measures emissions as a vehicle is operated at two different steady driving conditions, or modes, on a treadmill-like device called a dynamometer. Testing under load enables meaningful measurement of nitrogen oxide $\left(\mathrm{NO}_{\mathrm{X}}\right)$ emissions, and measurement of hydrocarbons $(\mathrm{HC})$ and carbon monoxide $(\mathrm{CO})$ under conditions more representative of on-road driving. Each mode of the ASM can last up to 170 seconds, but vehicles can "fast-pass" after any 10 consecutive seconds of emissions below the regulated levels or "cut points". Cut points for each mode vary by vehicle type, age, and weight. Increasingly more stringent $\mathrm{NO}_{\mathrm{X}}$ cut points have been phased in over time, starting with "Phase 3" of the enhanced program implementation in November 1998. Enhanced Smog Check testing occurs biennially with registration renewal, and when the vehicle changes ownership. Old vehicles (pre-1974) and the four newest model years are exempted. A complete description of the program is available from the Bureau of Automotive Repair (BAR), the agency responsible for overseeing Smog Check (www.smogcheck.ca.gov). 
California is required by law to evaluate its Enhanced Smog Check program to demonstrate equivalent effectiveness with EPA's preferred version of I/M (1). Numerous methods have been proposed or implemented for evaluating state I/M programs (2-5). EPA initially recommended that programs be compared with the Phoenix, AZ I/M program, since it most closely followed the original EPA proposal (2). However, changes to the Phoenix program in December 1999 make such a comparison impossible (see 6 for a discussion of other limitations with this approach). An EPA draft guidance document states that "the most accurate assessment of I/M program effectiveness will result from evaluations which combine multiple program evaluation methods," including both I/M test results and remote sensing measurements (3). This recommendation was reiterated in a National Research Council study of I/M program evaluation methods (5).

The California Air Resources Board (CARB) is the agency responsible for performing the formal evaluation of Smog Check for EPA (7). However, an independently appointed I/M Review Committee (IMRC) is mandated to periodically assess the program and recommend changes. The IMRC initiated a review in 1999 by contracting with researchers at Lawrence Berkeley National Laboratory. The complete results from the evaluation are publicly available (8). This paper describes the calculation of overall program benefits.

\section{Approach}

Overview. The primary benefits of Smog Check are the emissions prevented or avoided through the mechanisms of pre-inspection maintenance, repairs following failed tests, and the migration or accelerated retirement of malfunctioning vehicles. We estimated the benefits from each mechanism using a "bottom-up" approach that compares average per-vehicle emission rates of vehicles passing through the program to those that would pertain without Smog Check. The effects of Smog Check on both initial emissions and on the deterioration of emissions over a two-year cycle were considered. Emission rates were derived from an analysis of Smog Check test records contained in the Vehicle Information Database (VID) and from roadside testing performed by the BAR for the purpose of program evaluation. The number of vehicles affected by each mechanism was determined from the VID. Emissions, vehicle counts, and per-vehicle activity (fuel used) were resolved by model year. 
We estimated total exhaust benefits for two years of a single cycle of California's Enhanced Smog Check program circa 1999. The effects of one cycle may persist beyond two years, but such benefits are difficult or impossible to separate from those achieved in the next cycle. Onecycle benefits are lower than cumulative program benefits since cumulative benefits include carryover from past Smog Check cycles, e.g., from vehicles that were repaired previously and maintain lower emission levels. The estimation of cumulative benefits was deemed impractical since it requires comparison to a reference fleet similar in every way to the tested fleet, but not having ever been part of an I/M program. It is also relevant to discuss the incremental benefits of the Enhanced program in comparison to those that would have been achieved if the "Basic" twospeed idle program had been continued. An analysis of this type was included in the full report to the IMRC (8).

All of the required initial emission rates and several of the required deterioration rates were derived directly from measured Smog Check program or roadside test results. However, we were forced to make assumptions about several key parameters. Our approach is to state clearly where assumptions were needed, which assumptions were made for our "best" estimate, and to indicate the sensitivity of our results to the assumed parameter through the calculation of "high" and "low" benefits estimates.

Our analysis is designed to account for two important factors not captured by a simple comparison of initial and final Smog Check test results. The latter compares only the step change in emission rates at the time of the Smog Check test, whereas it is the total mass emissions of vehicles over time that is of interest for pollution control. Our approach considers how Smog Check alters deterioration patterns for repaired vehicles and the effect that reduced deterioration can have on the total emission reductions achieved over a two-year cycle.

Our approach also accounts for the selection bias in fleet-average emissions measured during $\mathrm{I} / \mathrm{M}$ testing that requires only a single passing test. Since malfunctioning vehicles can have highly variable emissions (9-11), some will pass an initial I/M test even if their overall average emissions are above the standard. Other vehicles with intermittent malfunctions may fail a first test but pass a re-test without being repaired. The selective acceptance of only passing test results gives the appearance of an emission reduction, without any real change in emissions. Selection bias directly affects only those vehicles that fail their initial test and pass a subsequent 
test without being repaired, yet the apparent (unrealized) reduction would bias the overall I/M benefit estimated for the fleet.

Data Sources. The result of every Smog Check inspection is sent automatically to the centralized Vehicle Information Database, which contains a complete record of nearly every vehicle's I/M history since the inception of the VID. At the request of the IMRC, the Bureau of Automotive Repair (BAR) provided VID data for this analysis. Specifically, we used $\sim 4.5$ million records from the 11 months of testing for which Phase $3 \mathrm{NO}_{\mathrm{X}}$ cut points applied, from 11 November 1998 through 3 October 1999. The VID data were screened extensively for data quality and consistency $(8)$. The focus was on identifying records with questionable emissions data (impossibly high or low values beyond the effect of measurement uncertainty) or invalid vehicle identification numbers. The data were then analyzed to identify the beginning and end of each Smog Check test cycle for each vehicle. Eighty-six percent of all vehicles tested under the Phase 3 cut points passed an initial inspection (initial-pass fleet). To determine how many of the failing vehicles eventually passed, we identified all vehicles that failed an initial test during the first two months of the Phase 3 period. Over the next 10 months, $\sim 90 \%$ of these vehicles (13\% of the entire fleet) passed a subsequent test (fail-pass fleet). No passing test was recorded for the remaining $10 \%$ (1.3\% of the original fleet); these vehicles are referred to as the "no-final-pass" fleet.

Approximately 69,000 vehicles were identified as passing through two or more Smog Check cycles during the period of study; these are henceforth called the "multi-cycle" fleet. In most cases the two likely included one biennial and one change-of-ownership cycle.

To assist with our analysis the BAR also provided records from $\sim 30,000$ roadside Smog Check tests performed between February 1997 and October 1999. The data were collected by BAR for the purpose of program evaluation. In the roadside test program, drivers were flagged from traffic and asked to voluntarily submit their vehicles to an on-the-spot Enhanced Smog Check. Testing included visual and functional inspections and an emissions test of full duration (no fast-pass) on a portable dynamometer. Test sites were located throughout Enhanced I/M areas of the state, and older vehicles were over-sampled to provide more accurate estimates of their emission levels. Additional details about this test program are available from BAR $(12,13)$. The data were screened for invalid emissions or vehicle identification data; very few bad records were detected. 
Limited on-road remote sensing data were also collected for use in the Smog Check program analysis, consisting of measurements for approximately 150,000 vehicles at sites in Sacramento, San Jose, and Los Angeles. Our use of these data for the analysis reported here was limited to an investigation of the number of no-final-pass vehicles that remain on the road indefinitely; additional analysis of these data is presented in (8).

Smog Check emission results were used to calculate fuel-based mass emission rates for each vehicle test. Conversion to mass emission rates was necessary for the estimation of total mass emission reductions. The calculation, described in detail elsewhere $(8,14,15)$ uses a carbon balance to relate reported pollutant exhaust concentrations ( $\mathrm{ppm} \mathrm{HC}$, ppm $\mathrm{NO}_{\mathrm{X}}, \% \mathrm{CO}, \% \mathrm{CO}_{2}$ ) to the total carbon content of the fuel. Typical fuel properties were used to normalize emissions to fuel consumption. Gram-per-gallon emission factors were calculated for both ASM modes. This paper focuses on results from the "ASM-2525" mode, in which vehicles are driven at $25 \mathrm{mph}$ at $25 \%$ of the maximum load of the Federal Test Procedure.

Multi-Cycle Analysis. The multi-cycle data were analyzed to quantify the selection bias effect and to determine deterioration rates for vehicles after they pass through the Smog Check program. We analyzed the fail-pass fleet separately from the initial-pass fleet. For each group, average emissions were analyzed as a function of time between Smog Check cycles. Full details and results of the multi-cycle analysis are provided in the full report to the IMRC (8). Key results relevant to this study are described here. Critically, we found that $20 \%$ of the fail-pass vehicles in the multi-cycle fleet failed the initial test of a subsequent Smog Check cycle that occurred within two months; this approximate failure rate persisted for vehicles tested up to 10 months later and rose to only $25 \%$ for fail-pass vehicles tested again after 13 months. Average emissions of failpass vehicles were substantially higher on the initial test of the next cycle than they were on the final passing test of the previous cycle, as shown in Figure 1. These results occur largely from emission variability but other factors may contribute $(8,11,16)$. For the initial-pass fleet, $\mathrm{HC}$ and $\mathrm{CO}$ emissions measured on the first test of the second cycle were higher than those measured in the initial passing test of the earlier cycle; the discrepancy increased with time between cycles. In contrast, $\mathrm{NO}_{\mathrm{X}}$ emissions were consistently similar or slightly lower than those measured on the first cycle for more than a year between tests. Using the data for initial-pass vehicles, a deterioration factor over the first year (centered around 6 months) was calculated by comparing average initial emissions measured on a second Smog Check to those from a previous Smog 
Check that occurred 1-12 months prior. Deterioration factors were averaged for model years 1974-1980 and assumed to be 1.0 for $\mathrm{NO}_{\mathrm{X}}$ (Table S1, Supporting Information). The time-series data indicate a linear deterioration for initial-pass vehicles over $\sim 1$ year, with a leveling off in months11-13 (8). The deterioration factor was projected to 12 months to calculate emission levels in the second year of an I/M cycle. Use of the deterioration factors is described below.

Calculating Benefits. The benefits associated with each of the three processes were calculated as the emissions difference induced by Smog Check multiplied by the number of vehicles affected and an estimated per-vehicle activity over two years. Initial emissions and deterioration factors were estimated both for Smog Check and No Smog Check cases so that a difference could be calculated over time. The number of vehicles affected was determined directly from the 11 months of Phase 3 VID data, scaled to a two-year test cycle, and scaled again to account for the $5 \%$ of VID records with bad data formats. All-wheel drive vehicles that received two-speed idle tests because they could not be operated on the dynamometer were given the same credit as vehicles tested by ASM in the "best" and "high" benefits estimates, but no credit is given to them in the "low" estimate. These vehicles are assumed to have no $\mathrm{NO}_{\mathrm{X}}$ benefits in any of the estimates because the idle test does not measure $\mathrm{NO}_{\mathrm{X}}$. Vehicle activity was calculated using model-year average fuel economy estimates provided by CARB (Table S2, Supporting Information) and mileage accumulation rates estimated by BAR from an analysis of individual vehicle odometer readings in the VID.

Pre-inspection maintenance and repairs. We estimated the pre-inspection benefit by comparing roadside ASM emissions of 4,468 vehicles that participated in Smog Check and were measured at roadside up to one year before their initial Enhanced test, to the initial Smog Check test results in the VID for all vehicles tested during the Phase 3 cut points. These emissions data are provided in Table $\mathrm{S} 3$ of the Supporting Information and shown in Figure 2 for HC. An average emission rate was used for MY 1974 to 1980 vehicles in the roadside data to reduce the high uncertainty associated with individual model year averages calculated from the relatively few test records available $\left(55 \mathrm{~g} / \mathrm{gal} \mathrm{HC}, 555 \mathrm{~g} / \mathrm{gal} \mathrm{CO}\right.$, and $60 \mathrm{~g} / \mathrm{gal} \mathrm{NO} \mathrm{N}_{\mathrm{X}}$. Figure 2 indicates that most model years have higher emissions when measured on road up to one year (on average, 4 months) before their initial Smog Check than at the time of their initial Smog Check.

Pre-inspection benefits were calculated through MY 1989. For MY 1990 and newer vehicles, differences between the roadside and VID data were small for $\mathrm{CO}$ and $\mathrm{NO}_{\mathrm{x}}$ and $\mathrm{HC}$ 
emissions were consistently higher when measured at roadside (Figure 2). Inclusion of these data would indicate a pre-inspection $\mathrm{HC}$ disbenefit for newer vehicles, a possible but improbable result. Rather, we suspect that differences in HC emissions for MY 1990 and newer vehicles results because some were allowed to fast-pass the official Smog Check test in the VID, while all were given a full ASM test at the roadside. For properly functioning vehicles that are not fully warmed up at the start of their Smog Check tests, emissions will decrease as the test progresses and full-test emissions will be lower than the first 10 consecutive seconds measured below the standard. It follows that average VID emissions for all model years might be lower if vehicles received the full ASM test. This in turn suggests that we may be understating the effect of preinspection repairs across the board.

Figure 2 shows average emissions for all vehicles participating in Smog Check, not just the portion that received pre-inspection repairs. These emission differences were assumed to apply across the initial-pass fleet with the assumption that deterioration after pre-inspection repairs is the same as it would have been without them. This is a highly uncertain assumption as there are no data with which to evaluate it. Vehicles that actually received pre-inspection maintenance and repairs experienced average emission reductions much larger than those indicated by Figure 2 . The lower emissions measured at the initial Enhanced Smog Check test (relative to roadside) may have resulted from other factors, including special preparation of vehicles to pass Smog Check without lasting repairs, fraudulent VID test results, or bias in the roadside sample. We assume that $75 \%$ of the emission differences result from actual pre-inspection maintenance and repairs (best estimate). Our low and high estimates attribute $50 \%$ or $100 \%$ of the apparent differences to be real reductions. The reasoning is that pre-conditioning and test fraud are known to occur but not to be so widespread.

Post-failure repair. Emission reductions resulting from post-failure repair were estimated primarily from the multi-cycle data and analysis. The assumptions used in our best (dashed lines), low (solid lines), and high (dotted lines) estimates are shown for MY 1985 vehicles in Figure 3. In all three estimates, initial after-repair emissions of the fail-pass fleet were estimated from the initial test of the second cycle for the multi-cycle fleet, rather than from the final passing result of the first cycle, to account for selection bias (from 31 to $19 \mathrm{~g} / \mathrm{gal}$ in Figure 3; see Table S4, Supporting Information). Analysis of the multi-cycle data demonstrated that after an initial increase following their first Smog Check cycle, emissions of fail-pass vehicles remained 
relatively constant for the next 12 months (8); emissions of fail-pass vehicles are thus known to be approximately constant for a year following the passing test (no deterioration). For the second year of the cycle, our best estimate assumption was that fail-pass vehicles deteriorate at the same rate that initial pass (multi-cycle) vehicles deteriorate following their initial cycle (from 19 to 23 g/gal in Figure 3; see Table S1, Supporting Information). Our high benefit estimate assumed no deterioration of fail-pass vehicle emissions in year 2, while our low estimate assumed deterioration back to initial test emission levels by the end of year 2 (from 19 to $31 \mathrm{~g} / \mathrm{gal}$ in Figure 3).

Next we estimated the two-year emission profile that fail-pass vehicles would experience without the Smog Check program. We used the initial, failing emissions test results of the multicycle, fail-pass fleet as a starting point for all fail-pass vehicles, and made assumptions about deterioration. For our best estimate, we assumed that the emissions of these vehicles would reach the level of the no-final-pass fleet (55 g/gal in Figure 3$)$ by the end of the two-year period. We assumed a stable average emission rate (no deterioration) for our low estimate. For the high estimate, emissions were assumed to reach no-final-pass levels in one year then remain constant through the second year. The number of fail-pass vehicles was determined directly from the VID. The areas A and B in Figure 3 demonstrate the low estimate of post-failure repair, areas A through $\mathrm{E}$ demonstrate the best estimate, and areas A through $\mathrm{H}$ demonstrate the high estimate.

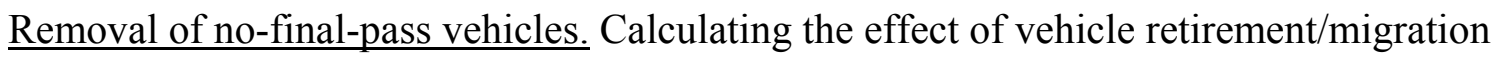
requires estimates of the number of vehicles affected, a two-year emission profile for vehicles that are removed, and an emission profile for the replacement vehicles. Emissions of no-finalpass vehicles were assumed to remain constant in the absence of Smog Check. In the best and high benefits estimates, replacement vehicles were assumed to have initial emissions of the initial-pass fleet, and to deteriorate over both years at the rate of the initial-pass fleet. In the best estimate, we assumed replacement of the same age, while in the high estimate we assumed replacement vehicles were 5 years newer. The low estimate assumed replacement by same-age vehicles from the fail-pass fleet, using emissions from the initial test of the second cycle from the multi-cycle data. These vehicles were assumed to have stable emissions over year 1 - which is consistent with multi-cycle results - and to deteriorate to no-final-pass levels over the course of the second year in the low estimate. 
As mentioned previously, the overall no-final-pass rate was $1.3 \%$ of the vehicles (or $10 \%$ of the failed vehicles) tested during the first 2 months of Phase 3 cut points. To the extent that some vehicles passed at a later time (>10-12 months later), this could be an overestimate of the nofinal-pass rate. Nevertheless, we used the same approach to calculate a no-final-pass rate for each model year. The no-final-pass rate increased by vehicle age, from $\sim 5 \%$ for 1990 and newer vehicles to over $17 \%$ for 1982 and older vehicles. Analysis of data from an on-road remote sensing study suggests that about one-third of the no-final-pass vehicles were still being driven in Enhanced areas one year after their last failing Smog Check (8). We therefore estimated the total number of removed vehicles as two-thirds of the no-final-pass fleet from the VID during Phase 3 testing, scaled up to a full two-year Smog Check cycle (see Table S5, Supporting Information). Benefits were calculated as if removal occurred at the beginning of the two-year cycle, i.e. after the initial failing test, even though removal likely took some time. The number of no-final-pass vehicles included those receiving two-speed idle tests with an adjustment for bad records.

Total baseline emissions. As a reference point for the estimated emission reductions, we calculated baseline running exhaust emissions for the fleet of vehicles participating in Smog Check over a two-year cycle. Starting with emissions measured during the roadside testing, we assumed that in the absence of Smog Check the fleet would deteriorate at the rate of initial-pass vehicles, as determined from the multi-cycle analysis. Emission rates (g/gal) over the first year were calculated by model year as the product of the measured roadside emission rate (Table S3, Supporting Information) and a deterioration factor to calculate emission levels at 6 months (Table S1, Supporting Information). Emission rates for the second year were calculated using a deterioration factor for 12 months, i.e. assuming that the vehicles would deteriorate to this level over the first year then maintain stable emissions during the second year. The number of vehicles affected by the program was calculated as the sum of the initial-pass, fail-pass, and no-final-pass groups.

\section{Results}

Importance of selection bias. Selection bias affected but did not dominate the change in $\mathrm{HC}$ and $\mathrm{CO}$ emissions observed between the initial failing and the final passing test of the first Smog Check cycle for fail-pass vehicles. This result, shown in Figure 1, is inferred by comparing both the first cycle passing emissions and the initial emissions measured on a second Smog Check 
cycle within twelve months, to the initial failing emissions. Actual emission reductions were about two-thirds to three-quarters of those predicted by the direct comparison of initial and final Smog Check test results (41 vs. $57 \%$ for $\mathrm{HC}$ and 59 vs. $79 \%$ for CO).

Mass emission reductions. Benefits were calculated as the average daily emission reduction over two years following an Enhanced Smog Check with Phase $3 \mathrm{NO}_{\mathrm{X}}$ cut points; they represent the daily reduction that would be observed from an on-road fleet of vehicles distributed throughout their biennial Smog Check cycle. Overall benefits are summarized in Table 1.

These results suggest that repair of vehicles that fail their initial official Smog Check likely accounts for the largest fraction of benefits (50\% to 65\%, depending on pollutant), but that maintenance and repair prior to official tests and pre-tests also contributes a large fraction of total benefits (30\% to 40\%). Removal from Enhanced areas of vehicles that fail initially but never pass appears to contribute much less to total benefits, about $5 \%$ to $10 \%$. Overall, the estimated reductions represent a substantial fraction of the emissions that would have occurred from these vehicles in the absence of Smog Check: $\mathrm{CO}$ was reduced by one-third, $\mathrm{HC}$ by onefourth and $\mathrm{NO}_{\mathrm{X}}$ by one-seventh.

Figures 4 through 6 show the best estimate of benefits by process and model year. These figures indicate that each of the three mechanisms affects vehicles across much of the age distribution, but not to the same degree. For both $\mathrm{CO}$ and HC, pre-inspection appears to be more important for the oldest vehicles compared with middle age vehicles. It is also interesting that substantial retirement benefits were indicated for almost all model years, without a clear trend of increasing retirement with increasing age. As mentioned, pre-inspection $\mathrm{HC}$ and $\mathrm{CO}$ benefits could not be determined for 1990 and newer vehicles.

The distribution of emission reductions by vehicle model year is summarized in Figure 7. The figure indicates that in 1999-2000 the large majority of benefits were obtained from MY 1980 to 1990 vehicles (10 to 20 years old). Substantial reductions, particularly in $\mathrm{HC}$ emissions, were obtained from vehicles more than 20 years old, but few benefits appear to result from testing of vehicles that were 5 to 9 years old in 1999 (MY 1991 through 1995).

The "efficiency" of testing vehicles from each model year is shown implicitly in Figure 7, and explicitly in Figure 8. Figure 7 indicates, for example, that $83 \%$ of estimated $\mathrm{NO}_{\mathrm{X}}$ benefits, $93 \%$ of estimated CO benefits, and $91 \%$ of estimated HC benefits are obtained from only the oldest 54\% of the vehicles currently eligible for testing (model years 1989 and older). Figure 8 
shows tons per day of emissions reductions per 100,000 vehicles tested in each model year. The figure indicates that testing of the oldest vehicles is most efficient for $\mathrm{HC}$ reductions, but $\mathrm{NO}_{\mathrm{X}}$ reductions are more efficiently obtained from middle-aged (10- to 20-year-old) vehicles.

\section{Discussion}

Data sources. The VID is uniquely valuable because it includes emission test results for nearly the entire population of vehicles participating in Enhanced Smog Check; as a result, there is no sample bias. The large numbers of vehicles allowed for analysis of benefits by vehicle model year. However, the VID may include biased emission measurements resulting from the fast-pass system and technician behavior. For example, some technicians may attempt to "help" vehicles pass with special conditioning procedures, or may fraudulently substitute a known clean vehicle in place of a suspected failing vehicle (clean-piping). The multi-cycle data contained in the VID were especially valuable for the study of selection bias and for determining deterioration rates of fail-pass and initial-pass vehicles for a year or more beyond their first I/M cycle.

The roadside data were a valuable complement to the VID. They were used to estimate preinspection benefits that could not be assessed with VID data only, and to calculate total baseline emissions. Roadside data are not subject to the measurement biases of fast-pass and technician behavior, but the sample of vehicles tested may not accurately represent the population of vehicles participating in California's Enhanced program. The number of vehicles tested was somewhat problematic when attempting to deconstruct the fleet, e.g. for model-year specific analyses, and potential sampling biases were revealed when the roadside data were used independently to estimate Smog Check program benefits (see reference 8).

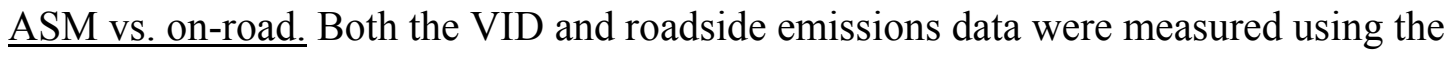
steady-load ASM test. The mass emission reductions and baseline emission totals are thus ASMbased estimates. To the extent that vehicle emissions on the ASM are correlated to those that occur during typical on-road transient driving, the calculated mass emission reductions will also correlate to real-world values, though likely not on a one-to-one basis. ASM emission test results have been statistically related to emission results from the same vehicles tested on the Federal Test Procedure (17). Correlations were also observed between ASM test results and remote sensing measurements of the same sample of vehicles, grouped by model year ( 8$)$. In studies of emissions variability by driving mode $(14,15)$, mild to moderate loads similar to that 
encountered on the ASM generally result in $\mathrm{HC}, \mathrm{CO}$ and $\mathrm{NO}_{\mathrm{X}}$ emissions that are lower than those encountered at higher loads. Under lower loads and decelerations, HC is typically higher and $\mathrm{NO}_{\mathrm{X}}$ is lower than at ASM-type loads. Thus, to the extent that Smog Check has induced successful repairs, as indicated by reductions in ASM emissions, the actual mass emission reductions across the full range of on-road driving could be even higher than those shown in Table 1; under this scenario baseline emissions would also be higher and the percent reductions might differ.

An alternate possibility is that observed emission reductions on the ASM test are not fully applicable to other driving conditions. A preliminary analysis of the limited remote sensing data collected in support of this study indicated much smaller emission reductions during some onroad driving than were seen from the VID and roadside ASM data (8).

Comparison to other studies. It is desirable to compare the results of our analysis to those of other I/M programs. However, direct comparisons may be misleading since our approach is fundamentally different than those that have been used in the past. One such study used remote sensing to estimate percentage emission reductions achieved during the first year of Colorado's Enhanced I/M program $(18,19)$. The authors compared emissions of odd model year vehicles that had been tested during the initial year of the program to even model year vehicles that had not been tested. A statistically significant but very small benefit $(<10 \%)$ was seen for $\mathrm{CO}$ and no difference was discernible for $\mathrm{HC}$ or $\mathrm{NO}_{\mathrm{X}}$. A similar study in Chicago found a similar percentage reduction in $\mathrm{CO}$, but a $14 \%$ reduction in $\mathrm{HC}(20)$. An analysis of the Phoenix I/M program used large number of remote sensing measurements to calculate a $7 \%$ reduction in fleet-average $\mathrm{CO}$ emissions during three-month periods before versus after a vehicle's I/M test (there are questions regarding the accuracy of the $\mathrm{HC}$ measurements, and $\mathrm{NO}_{\mathrm{X}}$ was not measured) (21). This analysis also found a substantial reduction in remote sensing $\mathrm{CO}$ emissions within 3 weeks prior to the initial I/M test, presumably due to pre-inspection maintenance and repair.

The Phoenix study also compared initial and final $\mathrm{I} / \mathrm{M}$ test results and found reductions of $\sim 13 \%$ for $\mathrm{HC}$ and $\mathrm{CO}$, and $6 \%$ for $\mathrm{NO}_{\mathrm{X}}$. These estimates assumed that all no-final-pass vehicles remained in the I/M area. The analysis of I/M test results thus found $\mathrm{CO}$ emission reductions nearly twice those estimated using remote sensing measurements; possible explanations are the different distribution of loads under which vehicles are tested in each measurement method, and the decrease in emission reductions as measured by remote sensing as time elapsed from the 
passing I/M test. A comparison of initial and final Smog Check results using the California Smog Check data yielded repair benefits of 19,39 , and $12 \%$ for $\mathrm{HC}, \mathrm{CO}$, and $\mathrm{NO}_{\mathrm{X}}$ respectively.

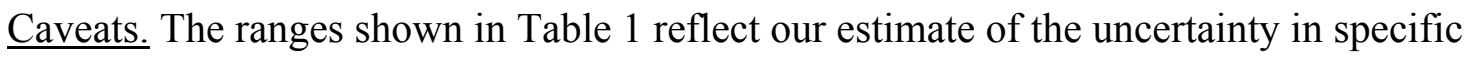
assumptions, e.g. the rate of fleet deterioration that would occur without Smog Check. The following additional uncertainties could not be quantitatively evaluated.

- Deterioration in the overall fleet may not be the same as in the multi-cycle fleet, even though first cycle model-year resolved initial emissions of the multi-cycle fleet were the same or slightly lower than emissions of the overall fleet (8).

- Some emission reductions attributed to Smog Check may result from maintenance and repairs that would have occurred without the I/M program.

- Vehicles receiving two-speed idle tests may not achieve the same emission reductions as those tested on the ASM.

- The estimate of repair benefits accounts for selection bias in the after-repair emissions of failpass vehicles, but not for selection bias in the initial, failing emissions test. This effect is examined in $(8)$.

- Benefits may be lower than predicted because of delays in vehicle repair or removal following a failed Smog Check.

- Fleet turnover will reduce emissions in parallel to the Smog Check program.

- Calculated benefits by model year are sensitive to estimated fuel-economy and annual travel.

This study was intended both as a demonstration of a novel approach for I/M evaluation and as an analysis of California's Enhanced I/M program. The method itself is valuable for several reasons. First, it allows for an assessment of benefits from pre-inspection repairs, which were shown to be substantial in California. Second, the method explicitly estimates mass emission reductions over time. Improving on methods that focus only on the step change in emissions that are induced by I/M testing, our method accounts for the apparently substantial effects that I/M can have by lowering deterioration rates of repaired vehicles. Third, the method accounts for the effect of selection bias when estimating emission reductions from I/M test data.

Additionally, the method provides policy-relevant information on the relative importance of the mechanisms through which I/M programs reduce emissions. For example, in the case of California's Smog Check program, the forced retirement of vehicles that did not pass contributed only a small portion of the total benefits. This result indicates that tracking down those vehicles 
that remain in the area after failing to pass an I/M test may be desirable from an equity perspective, but the potential emission reductions are relatively small. The analysis of emission benefits by model year also provides potentially valuable policy insights for California. Testing of vehicles that were 5-10 years old appears to be relatively inefficient whereas testing and repair of older vehicles appears to be highly efficient. This type of analysis could be used as a basis for extending the I/M grace period for newer vehicles or extending the testing requirements to older vehicles.

\section{Acknowledgements}

We thank Etan Gumerman for assistance with VID analyses and acknowledge the intellectual contributions of Etan, Robert Slott and Robert Sawyer to the Enhanced Smog Check study. Joel Schwartz, IMRC members, and CARB staff provided thoughtful comments and suggestions. We gratefully acknowledge the extensive support of BAR staff. This analysis was funded by the California IMRC and CARB, with additional support from the U.S. Department of Energy under Contract No. DE-AC03-76SF00098.

\section{References}

1. IM240 \& Evap Technical Guidance. U.S. Environmental Protection Agency, Office of Air and Radiation, Office of Transportation and Air Quality; U.S. Government Printing Office: Washington, DC, 1998; EPA420-R-98-010. Available on the web at: http://www.epa.gov/otaq/regs/im/im24f98.pdf (accessed Dec 2002)

\section{Development of a Proposed Procedure for Determining the Equivalency of Alternative} Inspection and Maintenance Programs. Final Report for U.S. Environmental Protection Agency; Sierra Research, Inc: Sacramento, CA, 1997; Sierra Research report number SR97-11-02. Available on the web at: http://www.epa.gov/otaq/regs/im/sr971102.pdf (accessed Dec 2002)

\section{Draft Guidance on Use of In-Program Data for Evaluation of I/M Program Performance.}

U.S. Environmental Protection Agency, Office of Air and Radiation, Office of Transportation and Air Quality; U.S. Government Printing Office: Washington, DC, 2001; EPA420-P-01-003. Available on the web at: http://www.epa.gov/otaq/regs/im/obd/p01003.pdf (accessed Dec 2002) 
4. Guidance on Use of Remote Sensing for Evaluation of I/M Program Performance. U.S. Environmental Protection Agency, Office of Air and Radiation, Office of Transportation and Air Quality; U.S. Government Printing Office: Washington, DC, 2002; EPA420-B-02-001. Available on the web at: http://www.epa.gov/otaq/regs/im/obd/b02001.pdf (accessed Dec 2002)

5. Evaluating Vehicle Emissions Inspection and Maintenance Programs. National Research Council; National Academy Press: Washington, DC, 2001. Available on the web at: http://www.nap.edu/books/0309074460/html/ (accessed Dec 2002)

6. Review of Sierra Research Report "Development of a Proposed Procedure for Determining the Equivalency of Alternative Inspection and Maintenance Programs". Report to U.S. Environmental Protection Agency; Tom Wenzel and Robert Sawyer, Lawrence Berkeley National Laboratory: Berkeley, CA, 1998; LBNL report number LBNL-44045. Available on the web at: http://www.epa.gov/otaq/regs/im/lblrevw.pdf (accessed Dec 2002)

7. Evaluation of California's Enhanced Vehicle Inspection and Maintenance Program (Smog Check II). California Environmental Protection Agency, Air Resources Board, Sacramento, CA, 2000. Available on the web at: http://www.arb.ca.gov/msprog/smogchk2/smogchk2.htm (accessed Dec 2002)

8. Wenzel, T.; Singer, B.; Gumerman, E.; Slott, R.; Sawyer, R. Section III: Evaluation of the Enhanced Smog Check Program: A Report to the California Inspection and Maintenance Review Committee. Final report for the California Inspection and Maintenance Review Committee; Lawrence Berkeley National Laboratory: Berkeley, CA, 2000; LBNL-46117. Available on the web at:

http://www.autorepair.ca.gov/stdPage.asp?Body=/IMRC/Pubs/IMRC20000619TOC.htm\&title= CA DCA BAR IMRC Full Report (accessed Dec 2002)

9. Knepper, J.C.; Koehl, W.J.; Benson, J.D.; Burns, V.R.; Gorse Jr., R.A.; Hochhauser, A.M.; Leppard, W.R.; Rapp, L.A.; Reuter, R.M. Fuel Effects in Auto/Oil High Emitting Vehicles. SAE Tech. Paper Series, 930137, 1993.

10. Bishop, G.A.; Stedman, D.H.; Ashbaugh, L. J. Air Waste Manage. Assoc. 1996, 46, 667. 
11. Wenzel, T.; Singer, B.C.; Slott, R. J. Trans. Stat. 2000, 3 (2), 1. Available on the web at: http://www.bts.gov/publications/jts/v3n2/paper1/1wenzel.pdf (accessed Dec 2002)

12. Roadside Inspection Program, Smog Check Performance Evaluation. California Bureau of Automotive Repair; Sacramento, CA, 2000. Available on the web at:

http://www.epa.gov/otaq/regs/im/roadside.pdf (accessed Dec 2002)

13. Smog Check Station Performance Analysis. California Bureau of Automotive Repair; Sacramento, CA, 2000. Available on the web at:

http://165.235.17.9/ftp/pdfdocs/station_performance.pdf (accessed Dec 2002)

14. Singer, B.C.; Harley, R.A. J. Air \& Waste Manage. Assoc. 1996, 46 (6), 581.

15. Singer, B.C. Ph.D. Dissertation, University of California at Berkeley, 1998 (Chapter 5).

16. Wenzel, T.; Brown, N. Can More Frequent Testing Improve I/M Program Effectiveness? Analysis of the Effect of Annual Testing in the Phoenix IM240 Program. Final Report to Environmental Systems Products, Inc; Lawrence Berkeley National Laboratory: Berkeley, CA, 2001; LBNL-47754.

17. DeFries, T.H.; Palacios, C.F.; Kishan, S.D.; Williamson, H.J. Models for Estimating California Fleet FTP Emissions from ASM Measurements. Draft report to California Bureau of Automotive Repair; Austin, TX, 1999.

18. Stedman, D.H.; Bishop, G.A.; Aldrete, P.; Slott, R.S. Environ. Sci. Technol. 1997, 31, 927.

19. Stedman, D.H.; Bishop, G.A.; Slott, R.S. Environ. Sci. Technol. 1998, 32, 1544.

20. Pokharel, S.S.; Bishop, G.A.; Stedman, D.H. On-Road Remote Sensing of Automobile Emissions in the Chicago Area: Year 3. Prepared for Coordinating Research Council, Inc., contract no. E-23-4; Denver, CO, 2000. Available on the web at: http://www.feat.biochem.du.edu/assets/databases/Illinois/Arlhghts/Chicago_Year_3_CRC99.pdf (accessed Dec 2002)

21. Wenzel, T. Environ. Sci \& Policy 2001, 4, 359. 
Table 1. Estimated one-cycle benefits from Enhanced Smog Check, in tons per day of emissions prevented (see text for details on methods and uncertainties). Best estimate is in bold. Ranges represent estimated uncertainty in key assumptions used to calculate the best estimates, e.g. in the fleet deterioration that would occur in the absence of Smog Check.

\begin{tabular}{|c|c|c|c|c|}
\hline Process & $\begin{array}{c}\text { Number of } \\
\text { vehicles } \\
\text { affected }\end{array}$ & $\mathrm{HC}$ & $\mathrm{CO}$ & $\mathrm{NO}_{\mathrm{X}}$ \\
\hline Pre-inspection & $4,588,471^{*}$ & $33(19-44)$ & $645(380-860)$ & $23(16-34)$ \\
\hline Post-test repair & $666,942 \#$ & $54(18-72)$ & $890(340-1170)$ & $53(40-53)$ \\
\hline $\begin{array}{c}\text { No-final-pass } \\
\text { removal }\end{array}$ & $99,325 \dagger$ & $10(9-11)$ & $165(150-180)$ & $5(4-8)$ \\
\hline All & $5,354,738$ & $97(46-128)$ & $1690(860-2200)$ & $81(60-91)$ \\
\hline $\begin{array}{c}\text { Total Baseline } \\
\text { Emissions }\end{array}$ & & 370 & 5010 & 570 \\
\hline$\%$ Reduction & & $26 \%(12-34 \%)$ & $34 \%(17-44 \%)$ & $14 \%(10-16 \%)$ \\
\hline
\end{tabular}

* Total number of initial-pass vehicles. The emissions of only 2,041,266 1974 to 1989 initialpass vehicles were affected by pre-inspection maintenance and repairs.

\# Total number of fail-pass vehicles.

$\dagger$ Total number of no-final-pass vehicles. The emissions of only 66,548 (two-thirds) no-finalpass vehicles were affected by vehicle removal and replacement. 


\section{Table/Figure captions}

Figure 1. Average emissions (g/gal) and emission reductions of fail-pass vehicles on initial (failing) test, final (passing) test, and subsequent initial test in next Smog Check cycle within next year. Difference in emissions from initial test in Cycle 1 and emissions from initial test in Cycle 2 used to estimate emission reductions from post-failure repair.

Figure 2. Average HC ASM2525 emissions (g/gal) by model year, used to estimate preinspection benefits. Difference between emissions measured at roadside pullover test up to one year prior to Smog Check test and initial Smog Check test assumed to be attributable to vehicle maintenance and repairs prior to initial Smog Check test. Horizontal lines are average emissions for model years 1974 through 1980.

Figure 3. Schematic representation of the approach used to estimate emission reductions from post-failure repair, using $\mathrm{HC}$ emissions of MY1985 vehicles as an example. The top group of lines shows deterioration scenarios that might occur without Smog Check; emissions start at the levels measured at the initial failing test. Emissions are assumed to either stay constant or rise to level of no-final-pass vehicles. The bottom group of lines starts at the postrepair emission levels measured during a second Smog Check cycle within one year, and reflects the measured absence of deterioration for these vehicles over approximately one year. Emissions in the second year after Smog Check are assumed either to remain constant, to deteriorate at the level measured for initial-pass vehicles, or to return to the (failing) levels initially measured for these vehicles.

Figure 4. Estimated HC emissions prevented by Enhanced Smog Check program. See text for details on approach used to calculate benefits from pre-inspection maintenance, post-failure repair, and removal of no-final-pass vehicles.

Figure 5. Estimated CO emissions prevented by Enhanced Smog Check program. See text for details on approach used to calculate benefits from pre-inspection maintenance, post-failure repair, and removal of no-final-pass vehicles.

Figure 6. Estimated $\mathrm{NO}_{\mathrm{x}}$ emissions prevented by Enhanced Smog Check program. See text for details on approach used to calculate benefits from pre-inspection maintenance, post-failure repair, and removal of no-final-pass vehicles.

Figure 7. Cumulative emission benefits and vehicles tested in Enhanced Smog Check, by vehicle model year. 1989 and older vehicles account for half of the fleet tested, and over $80 \%$ of the emission reduction benefits.

Figure 8. Estimated efficiency (ton per day reduction per 10,000 vehicles tested) of Enhanced Smog Check by vehicle model year. Emission reductions per vehicle tested are greater for older vehicles than for newer vehicles. 


\section{Supporting Information for}

\section{Estimated Emission Reductions from California's Enhanced Smog Check Program}

Brett C. Singer and Thomas P. Wenzel

The Supporting Information section includes tables of vehicle counts, activity assumptions, and average emissions by model year that were used to calculate the emissions benefits of the California Enhanced Smog Check program. 
Table S1. Estimated emissions deterioration factors over 6 and 12 months, from initial-pass vehicles in the multi-cycle fleet. Factors were used to estimate emissions deterioration after passing Enhanced Smog Check and if there were no Smog Check program.

\begin{tabular}{ccccccc}
\hline Model & \multicolumn{3}{c}{ Deterioration factors over 6 months } & \multicolumn{3}{c}{ Deterioration factors over 12 months } \\
Year & HC & CO & NOx & HC & CO & NOx \\
\hline 1974 & 1.26 & 1.45 & 1.00 & 1.52 & 1.89 & 1.00 \\
1975 & 1.26 & 1.45 & 1.00 & 1.52 & 1.89 & 1.00 \\
1976 & 1.26 & 1.45 & 1.00 & 1.52 & 1.89 & 1.00 \\
1977 & 1.26 & 1.45 & 1.00 & 1.52 & 1.89 & 1.00 \\
1978 & 1.26 & 1.45 & 1.00 & 1.52 & 1.89 & 1.00 \\
1979 & 1.26 & 1.45 & 1.00 & 1.52 & 1.89 & 1.00 \\
1980 & 1.26 & 1.45 & 1.00 & 1.52 & 1.89 & 1.00 \\
1981 & 1.26 & 1.45 & 1.00 & 1.52 & 1.89 & 1.00 \\
1982 & 1.26 & 1.45 & 1.00 & 1.52 & 1.89 & 1.00 \\
1983 & 1.26 & 1.45 & 1.00 & 1.52 & 1.89 & 1.00 \\
1984 & 1.26 & 1.45 & 1.00 & 1.52 & 1.89 & 1.00 \\
1985 & 1.22 & 1.45 & 1.00 & 1.43 & 1.89 & 1.00 \\
1986 & 1.19 & 1.32 & 1.00 & 1.38 & 1.64 & 1.00 \\
1987 & 1.17 & 1.36 & 1.00 & 1.35 & 1.71 & 1.00 \\
1988 & 1.15 & 1.22 & 1.00 & 1.30 & 1.43 & 1.00 \\
1989 & 1.11 & 1.11 & 1.00 & 1.22 & 1.22 & 1.00 \\
1990 & 1.06 & 1.00 & 1.00 & 1.12 & 1.00 & 1.00 \\
1991 & 1.06 & 1.00 & 1.00 & 1.12 & 1.00 & 1.00 \\
1992 & 1.06 & 1.00 & 1.00 & 1.12 & 1.00 & 1.00 \\
1993 & 1.06 & 1.00 & 1.00 & 1.12 & 1.00 & 1.00 \\
1994 & 1.06 & 1.00 & 1.00 & 1.12 & 1.00 & 1.00 \\
1995 & 1.06 & 1.00 & 1.00 & 1.12 & 1.00 & 1.00 \\
\hline
\end{tabular}


Table S2. Estimated average travel and fuel economy by model year for the California combined light and medium duty fleet of vehicles in calendar year 1999. Travel estimates were provided by the California Bureau of Automotive Repair. Fuel economy estimates were provided by the California Air Resources Board.

\begin{tabular}{ccc}
\hline $\begin{array}{c}\text { Model } \\
\text { Year }\end{array}$ & $\begin{array}{c}\text { Avg. Fuel } \\
\text { Economy } \\
\text { (miles /gal) }\end{array}$ & $\begin{array}{c}\text { Avg. Miles } \\
\text { traveled in } \\
\text { 1 year }\end{array}$ \\
\hline 1974 & 11.37 & 6027 \\
1975 & 11.63 & 6207 \\
1976 & 10.54 & 6448 \\
1977 & 10.35 & 6380 \\
1978 & 11.27 & 6512 \\
1979 & 11.65 & 6781 \\
1980 & 12.47 & 7066 \\
1981 & 13.82 & 7327 \\
1982 & 13.83 & 7959 \\
1983 & 14.44 & 8154 \\
1984 & 14.73 & 8471 \\
1985 & 17.02 & 8722 \\
1986 & 17.44 & 9061 \\
1987 & 17.82 & 9441 \\
1988 & 17.82 & 10032 \\
1989 & 17.05 & 10550 \\
1990 & 16.77 & 11103 \\
1991 & 16.94 & 11733 \\
1992 & 16.99 & 12375 \\
1993 & 17.64 & 12950 \\
1994 & 18.20 & 13577 \\
1995 & 18.15 & 14162 \\
\hline & & \\
\hline
\end{tabular}


Table S3. Number of vehicles and average emissions (ASM2525 test grams per gallon) of initial pass vehicles and vehicles measured at roadside up to one year prior to initial Enhanced Smog Check test. Data used to estimate reductions from pre-inspection maintenance and repairs.

\begin{tabular}{|c|c|c|c|c|c|c|c|c|c|}
\hline \multirow[b]{2}{*}{$\begin{array}{l}\text { Model } \\
\text { Year }\end{array}$} & \multicolumn{2}{|c|}{$\begin{array}{l}\text { Initial Pass vehicles } \\
\text { in Phase } 3 \text { ( } 327 \text { days) }\end{array}$} & \multirow{2}{*}{$\begin{array}{l}\text { Full year } \\
\text { Incl "bad" } \\
\text { records }\end{array}$} & \multicolumn{3}{|c|}{$\begin{array}{l}\text { Average emissions before pre-inspect } \\
\text { (from roadside data) }\end{array}$} & \multicolumn{3}{|c|}{$\begin{array}{l}\text { Average emissions of total fleet at initial } \\
\text { official Smog Check (from VID) }\end{array}$} \\
\hline & ASM & $\begin{array}{l}\text { Two-speed } \\
\text { idle }\end{array}$ & & $\mathrm{HC}$ & $\mathrm{CO}$ & NOx & $\mathrm{HC}$ & $\mathrm{CO}$ & NOx \\
\hline 1974 & 17186 & 3567 & 24323 & 42.83 & 584.8 & 72.16 & 38.51 & 441 & 58.82 \\
\hline 1975 & 12149 & 3202 & 17992 & 74.55 & 561.4 & 64.72 & 29.96 & 309.5 & 55.71 \\
\hline 1976 & 19615 & 4334 & 28069 & 61 & 371 & 53.43 & 29.24 & 282.7 & 59.24 \\
\hline 1977 & 28782 & 6430 & 41269 & 88.7 & 477.3 & 57.55 & 28.48 & 285.5 & 56.47 \\
\hline 1978 & 33760 & 7476 & 48329 & 68.65 & 572.1 & 60.42 & 28.13 & 278.3 & 55.81 \\
\hline 1979 & 39614 & 4753 & 51999 & 41.88 & 562.8 & 51.16 & 26.95 & 262.2 & 53.75 \\
\hline 1980 & 32162 & 3631 & 41950 & 27.14 & 639.6 & 68.24 & 25.36 & 323.5 & 54.36 \\
\hline 1981 & 36231 & 4083 & 47249 & 39.72 & 631.6 & 57.78 & 25.12 & 308.5 & 53.43 \\
\hline 1982 & 46488 & 5085 & 60445 & 36.41 & 641.5 & 61.09 & 24.34 & 276.4 & 54.58 \\
\hline 1983 & 62976 & 7087 & 82115 & 31.8 & 482.8 & 61.44 & 22.99 & 248.7 & 53.4 \\
\hline 1984 & 111766 & 11973 & 145024 & 33.02 & 480.2 & 54.79 & 21.76 & 256.6 & 48.68 \\
\hline 1985 & 149441 & 15014 & 192744 & 25.85 & 383.3 & 52.63 & 20.1 & 221 & 47.06 \\
\hline 1986 & 200061 & 18908 & 256636 & 18.32 & 203.7 & 47.33 & 17.13 & 162.9 & 42.42 \\
\hline 1987 & 228323 & 20351 & 291450 & 17.57 & 262.2 & 46.05 & 15.77 & 156.3 & 38.03 \\
\hline 1988 & 256888 & 23417 & 328523 & 16.64 & 160.3 & 39.29 & 13.61 & 105.2 & 33.09 \\
\hline 1989 & 302318 & 24596 & 383149 & 10.99 & 115.6 & 27.5 & 11.98 & 86.54 & 26.37 \\
\hline 1990 & 290060 & 27674 & 372390 & 7.932 & 64.81 & 21.61 & 10.54 & 66.85 & 22.44 \\
\hline 1991 & 290091 & 34654 & 380607 & 7.305 & 69.22 & 18.56 & 9.561 & 57.41 & 19.74 \\
\hline 1992 & 260463 & 36401 & 347930 & 7.521 & 72.44 & 18.68 & 8.568 & 48.08 & 16.45 \\
\hline 1993 & 298522 & 41502 & 398514 & 4.623 & 29.81 & 11.48 & 6.837 & 37.97 & 12.27 \\
\hline 1994 & 269426 & 35516 & 357398 & 4.547 & 21.31 & 10.29 & 5.532 & 26.83 & 10.1 \\
\hline 1995 & 529588 & 59452 & 690366 & 4.356 & 20.58 & 8.46 & 4.32 & 18.33 & 8.753 \\
\hline
\end{tabular}


Table S4. Number of vehicles and average emissions (ASM2525 test grams per gallon) of failpass vehicles that are re-tested in a second Smog Check cycle within 12 months, by model year. Difference between initial test in first and second Smog Check cycle used to estimate reductions from post-failure repair of vehicles.

\begin{tabular}{|c|c|c|c|c|c|c|c|c|c|}
\hline \multirow{2}{*}{$\begin{array}{c}\text { Model } \\
\text { Year }\end{array}$} & \multirow{2}{*}{$\begin{array}{c}\text { Actual vehicles } \\
\text { tested in } 327 \\
\text { days of Phase } 3\end{array}$} & \multirow{2}{*}{$\begin{array}{l}\text { Adjustment factor } \\
\text { to include two- } \\
\text { speed idle tests } \\
\end{array}$} & \multirow{2}{*}{$\begin{array}{l}\text { Scaled to one full } \\
\text { year plus "bad" } \\
\text { records } \\
\end{array}$} & \multicolumn{3}{|c|}{$\begin{array}{l}\text { Initial (failing) test of first } \\
\text { cycle }\end{array}$} & \multicolumn{3}{|c|}{ Initial test of second cycle } \\
\hline & & & & $\mathrm{HC}$ & $\mathrm{CO}$ & NOx & $\mathrm{HC}$ & $\mathrm{CO}$ & NOx \\
\hline 1974 & 3253 & 1.24 & 4745 & 49 & 845 & 62 & 45 & 511 & 65 \\
\hline 1975 & 3390 & 1.31 & 5187 & 51 & 532 & 89 & 26 & 415 & 54 \\
\hline 1976 & 5364 & 1.29 & 8113 & 62 & 448 & 81 & 40 & 219 & 60 \\
\hline 1977 & 8549 & 1.28 & 12825 & 43 & 433 & 61 & 29 & 262 & 47 \\
\hline 1978 & 11027 & 1.27 & 16464 & 42 & 556 & 69 & 24 & 257 & 43 \\
\hline 1979 & 14311 & 1.24 & 20807 & 43 & 559 & 66 & 27 & 247 & 47 \\
\hline 1980 & 11717 & 1.20 & 16437 & 35 & 540 & 76 & 19 & 232 & 50 \\
\hline 1981 & 17010 & 1.18 & 23621 & 33 & 506 & 69 & 19 & 202 & 43 \\
\hline 1982 & 21799 & 1.16 & 29535 & 34 & 467 & 75 & 19 & 194 & 47 \\
\hline 1983 & 27176 & 1.15 & 36703 & 32 & 459 & 76 & 18 & 161 & 45 \\
\hline 1984 & 44429 & 1.09 & 56967 & 32 & 487 & 71 & 18 & 192 & 43 \\
\hline 1985 & 51458 & 1.09 & 65782 & 31 & 472 & 73 & 19 & 193 & 42 \\
\hline 1986 & 51507 & 1.09 & 65781 & 30 & 371 & 71 & 17 & 144 & 41 \\
\hline 1987 & 55463 & 1.09 & 70566 & 28 & 393 & 65 & 16 & 144 & 38 \\
\hline 1988 & 45324 & 1.09 & 57917 & 25 & 273 & 63 & 15 & 123 & 34 \\
\hline 1989 & 40294 & 1.08 & 51066 & 24 & 237 & 57 & 15 & 113 & 31 \\
\hline 1990 & 28219 & 1.10 & 36230 & 25 & 237 & 54 & 15 & 100 & 30 \\
\hline 1991 & 22537 & 1.12 & 29554 & 23 & 228 & 48 & 15 & 75 & 27 \\
\hline 1992 & 15435 & 1.14 & 20608 & 23 & 246 & 44 & 14 & 71 & 26 \\
\hline 1993 & 13129 & 1.14 & 17519 & 20 & 167 & 36 & 11 & 56 & 19 \\
\hline 1994 & 6755 & 1.13 & 8963 & 16 & 148 & 33 & 9 & 62 & 17 \\
\hline 1995 & 8856 & 1.11 & 11552 & 14 & 159 & 29 & 7 & 39 & 14 \\
\hline
\end{tabular}


Table S5. Number of vehicles and average emissions (ASM2525 test grams per gallon) of nofinal-pass and initial-pass vehicles by model year. Two-thirds of the no-final-pass vehicles are assumed to be replaced with the average initial-pass vehicle five years younger, as a result of the Enhanced Smog Check program.

\begin{tabular}{|c|c|c|c|c|c|c|c|c|c|}
\hline \multirow[b]{2}{*}{$\begin{array}{c}\text { Model } \\
\text { Year }\end{array}$} & \multirow{2}{*}{$\begin{array}{c}\text { Actual vehicles } \\
\text { tested in } 327 \\
\text { days of Phase } 3\end{array}$} & \multirow{2}{*}{$\begin{array}{l}\text { Adjustment factor } \\
\text { to include two- } \\
\text { speed idle tests }\end{array}$} & \multirow{2}{*}{$\begin{array}{l}\text { Scaled to one full } \\
\text { year plus "bad" } \\
\text { records }\end{array}$} & \multicolumn{3}{|c|}{$\begin{array}{l}\text { No-final-pass vehicles, initial } \\
\text { failing test of first cycle }\end{array}$} & \multicolumn{3}{|c|}{$\begin{array}{l}\text { Initial-pass vehicles, initial } \\
\text { test of second cycle }\end{array}$} \\
\hline & & & & $\mathrm{HC}$ & $\mathrm{CO}$ & NOx & $\mathrm{HC}$ & $\mathrm{CO}$ & NOx \\
\hline 1974 & 683 & 1.24 & 996 & 156 & 1098 & 56 & 31 & 429 & 55 \\
\hline 1975 & 746 & 1.31 & 1142 & 109 & 951 & 56 & 30 & 255 & 56 \\
\hline 1976 & 1140 & 1.29 & 1724 & 108 & 896 & 58 & 22 & 238 & 55 \\
\hline 1977 & 1868 & 1.28 & 2802 & 99 & 908 & 53 & 20 & 228 & 52 \\
\hline 1978 & 2538 & 1.27 & 3790 & 83 & 936 & 57 & 23 & 192 & 50 \\
\hline 1979 & 3250 & 1.24 & 4725 & 91 & 962 & 56 & 20 & 178 & 49 \\
\hline 1980 & 3034 & 1.20 & 4256 & 76 & 1172 & 55 & 19 & 200 & 48 \\
\hline 1981 & 4310 & 1.18 & 5986 & 67 & 1015 & 61 & 23 & 194 & 48 \\
\hline 1982 & 5008 & 1.16 & 6786 & 62 & 895 & 69 & 19 & 175 & 45 \\
\hline 1983 & 5653 & 1.15 & 7635 & 58 & 898 & 68 & 18 & 145 & 46 \\
\hline 1984 & 8762 & 1.09 & 11234 & 56 & 986 & 63 & 18 & 166 & 42 \\
\hline 1985 & 8796 & 1.09 & 11244 & 55 & 946 & 63 & 17 & 143 & 40 \\
\hline 1986 & 7386 & 1.09 & 9432 & 52 & 822 & 67 & 14 & 113 & 37 \\
\hline 1987 & 7139 & 1.09 & 9083 & 51 & 861 & 62 & 14 & 108 & 33 \\
\hline 1988 & 5098 & 1.09 & 6515 & 48 & 651 & 64 & 12 & 88 & 30 \\
\hline 1989 & 3527 & 1.08 & 4470 & 47 & 571 & 66 & 11 & 76 & 24 \\
\hline 1990 & 2081 & 1.10 & 2672 & 43 & 432 & 70 & 10 & 61 & 21 \\
\hline 1991 & 1425 & 1.12 & 1870 & 38 & 383 & 67 & 9 & 53 & 19 \\
\hline 1992 & 835 & 1.14 & 1115 & 33 & 328 & 61 & 9 & 46 & 16 \\
\hline 1993 & 644 & 1.14 & 860 & 35 & 316 & 51 & 7 & 40 & 12 \\
\hline 1994 & 346 & 1.13 & 459 & 30 & 312 & 50 & 6 & 30 & 10 \\
\hline 1995 & 405 & 1.11 & 529 & 26 & 273 & 38 & 5 & 21 & 8 \\
\hline
\end{tabular}

